\title{
Is religious fasting related to iron status in Greek Orthodox Christians?
}

\author{
Katerina O. Sarri ${ }^{1}$, Anthony G. Kafatos ${ }^{2}$ and Siobhan Higgins ${ }^{1} *$ \\ ${ }^{1}$ Division of Developmental Medicine (Human Nutrition Section), Yorkhill Hospital, Dalnair Street, Glasgow G3 8SJ, UK \\ ${ }^{2}$ Department of Social Medicine, University of Crete, School of Medicine, PO Box 2208, Iraklion 71003, Crete, Greece
}

(Received 28 September 2004 - Revised 21 January 2005 - Accepted 22 February 2005)

\begin{abstract}
The Orthodox Christian diet is unique in regularly interchanging from an omnivore to a vegetarian-type diet, and no study to date has focused on the impact of this on Fe status. Thirty-five Greek Orthodox Christian strict fasters ( $n 17$ male, $n 18$ female; mean age $43.6 \pm 13.2$ years) and twenty-four controls ( $n$ 11 male, $n 13$ female; mean age 39.8 \pm 7.6 years) were studied before (pre) and near completion (end) of the Christmas fasting (CF) period (40 d), during which meat and dairy products are prohibited. Fe status was assessed using standard haematological parameters, and Fe deficiency was determined via serum ferritin levels $(<12 \mathrm{ng} / \mathrm{ml})$ and the tri-index model. While fasters had marginally poorer pre haematological indicators, values were well above the cut-off levels, suggesting that intermittent fasting for a mean of $22.5 \pm 15.5$ years did not have any substantial adverse effects on Fe status. During the $\mathrm{CF}$ period the changes in Fe status indices were more beneficial for fasters than for control subjects. In particular, fasters increased their ferritin levels $(P=0.02)$ and decreased their total Fe-binding capacity $(P<0 \cdot 001)$. Compared with males, the effect of CF was more pronounced in female fasters. No subjects were detected with Fe deficiency at the end of the CF period. End dietary Fe and fibre intake were significantly higher in the fasters as compared with the control group ( $P=0.038$ and $P=0.001$, respectively). Adherence to the Orthodox Christian dietary guidelines does not have a major impact on Fe status and is not associated with a significantly greater degree of Fe deficiency.
\end{abstract}

Iron status: Deficiency: Fasting: Vegetarian diet: Orthodox Christians

Currently, Fe deficiency and Fe-deficiency anaemia (IDA) are the most prevalent nutritional disorders in the world (Hercberg et al. 2001). However, few epidemiological data concerning this matter are available in European countries, and no data are available for Greece (Hercberg et al. 2001).

Vegetarian diets, compared with omnivore diets, have been associated with impaired Fe status in a number of studies (Leggett et al. 1990; Alexander et al. 1994; Donovan \& Gibson, 1995; Shaw et al. 1995), because of their inadequate intake of haem-Fe (Helman \& Darnton-Hill, 1987). The exclusion of meat not only removes the highly available $\mathrm{Fe}$, but also decreases the ability to counterbalance powerful inhibitors. Furthermore, Shaw et al. (1995) highlighted the importance of meat as a source of Fe by showing that non-vegetarian women who consumed only $74 \%$ as much $\mathrm{Fe}$ as vegetarians had a significantly better Fe status. Similarly, compared with omnivores, lacto-ovo-vegetarians and semivegetarians, whose diets do not contain any red meat, have been found to have significantly lower Fe stores and increased risk of poor Fe status (Donovan \& Gibson, 1995). Nevertheless, evidence as to the strength of the association of vegetarianism with impaired Fe status is still unclear, since several studies have found no evidence of such an association (Hunt, 2003). However, the evidence is more consistent when studies focusing on vegetarian women of childbearing age and children are considered (Hercberg et al. 2001; Patterson et al. 2001).

The diet of Greek Orthodox Christians is unique in interchanging from an omnivore to a vegetarian-type diet at regular intervals throughout the year. The Orthodox Church specifies dietary restrictions and fasting for a total of 180-200 d annually. One of the principal fasting periods in the Orthodox Christian Calendar is the one followed during Christmas, which lasts for $40 \mathrm{~d}$. During Christmas the 'faithful' are advised to avoid the consumption of meat (red meat and chicken), dairy products and eggs, while fish and olive oil are allowed except on Wednesdays and Fridays. Seafood such as shrimps, squid, cuttlefish, octopus, lobsters, crabs, as well as snails are allowed on all fasting days throughout the year. Therefore, the 'faithful' follow a periodic vegetarian-type of diet during the Christmas fasting (CF) in terms of the foods consumed during that period.

The purpose of the present study was to determine the effect of regular fasting over the course of a number of years (22.5 \pm 15.5 years) and the effect of a single fasting period (i.e. CF) for $40 \mathrm{~d}$ on Fe status in a group of strict Greek Orthodox Christian fasters, where a periodic vegetarian-type diet is prescribed by the Orthodox Christian Church. No previous study has ever examined the Fe status of this population before.

\section{Methods \\ Subjects and recruitment}

A total of 120 Greek Orthodox Christians participated in a large longitudinal study carried out in Crete, Greece in 2001 (Sarri et al. 2003, 2004). Only fifty-nine of them had measurements for 
Fe status indices and, therefore, were included in the present study. All the subjects were healthy, not taking any medication or supplements, including Fe supplements. Thirty-five of the subjects ( $n 17$ males, $n 18$ females; mean age $43.6 \pm 13 \cdot 2$ years; BMI $29.2 \pm 5.4 \mathrm{~kg} / \mathrm{m}^{2}$ ) were 'faithful' fasters, nuns, priests and lay persons, who had been vigorously adhering to the Orthodox Christian fasting practices and all the recommended fasting periods for a mean of $22.5 \pm 15.5$ years (fasting group). Twenty-four subjects ( $n 11$ males, $n 13$ females; mean age $39.8 \pm 7.6$ years; BMI $26.7 \pm 4.9 \mathrm{~kg} / \mathrm{m}^{2}$ ) constituted the control group. The control group did not fast at any period of the year. The fasting group was not significantly different from the control group with regard to age, sex or BMI. However, compared with the fasting group, a greater number of controls were smokers (50 v. $5.7 \%$ ), while the majority of the fasting group did not smoke $(94.3 \% ; P<0.001)$. Subjects gave written informed consent to participate in the study, and a full description of the study procedures is given in Sarri et al. (2003, 2004).

\section{Study design}

All subjects were examined and measured 1 week before the beginning (pre) and 1 week before the completion (end) of the $\mathrm{CF}$ period. All measurements were made between 8.00 hours and 10.00 hours and they included fasting blood collection (for biochemical analysis), anthropometric measurements (height, weight, waist:hip ratio, and blood pressure), the completion of a number of questionnaires regarding their fasting habits, their health status with regard to diabetes, CHD, hormonal disturbances and drug intake, and their health habits such as smoking and alcohol consumption, and the administration of a $24 \mathrm{~h}$ dietary recall by a trained dietitian. Participants were also asked to complete one $3 \mathrm{~d}$ weighed food record before each sample collection point. Details on the methods used for the anthropometric measurements, the dietary data collection and the food database used are available in previous publications (Sarri et al. 2003, 2004).

\section{Haematological measurements}

Seven main haematological indicators (serum ferritin, serum Fe, tranferrin saturation, mean corpuscular $\mathrm{Hb}$ concentration (MCHC), total Fe-binding capacity (TIBC), Hb and packed cell volume) were analysed in order to describe the $\mathrm{Fe}$ status of the subjects both before the beginning (pre) and before the completion (end) of the fasting period.

Fasting blood samples were obtained from subjects at both sample collection time points (pre and end). Samples of whole blood were sent immediately for the analysis of $\mathrm{Hb}$, packed cell volume and $\mathrm{MCHC}$ at the Department of Biochemistry at the Peripheral Hospital of Crete. The remaining sample was kept at room temperature for 30 to $45 \mathrm{~min}$ to allow it to clot, and then was centrifuged at $3000 \mathrm{rpm}$ for $10 \mathrm{~min}$ to separate the serum. Serum was separated into samples in cryotubes and stored frozen at $-80^{\circ} \mathrm{C}$ until analysed.

Serum ferritin was measured using an IMMULITE 2000 analyser (DPC, Los Angeles, CA, USA). Serum transferrin was measured by a commercially modified polyethylene glycol enhanced turbidimetric method. The percentage saturation of serum transferrin was calculated using a standard formula: serum $\mathrm{Fe}(\mu \mathrm{mol} / \mathrm{l}) / \mathrm{TIBC}(\mu \mathrm{mol} / \mathrm{l})$ (Tsung et al. 1975). TIBC was calculated from transferrin concentration $(\mathrm{g} / \mathrm{l}) \times 22.5$
(Waldmann et al. 2004). Serum Fe was measured by a spectrophotometric method following reaction of ferrous $\mathrm{Fe}$ with ferrozine (Seidel, 1984). The other indicators of $\mathrm{Fe}$ status $(\mathrm{Hb}$ concentration, packed cell volume and MCHC) were analysed by standard biochemical methods.

Fe deficiency was determined by low levels of serum ferritin $(<12 \mathrm{ng} / \mathrm{ml})$, or by the use of the tri-index model, recommended by Bindra \& Gibson (1986). This model is based on three independent tests of biochemical Fe status, representing the three different stages of Fe deficiency (serum ferritin $<12 \mathrm{ng} / \mathrm{ml}$ for depletion of $\mathrm{Fe}$ storage, serum transferrin saturation $<16 \%$ as an indicator of reduced $\mathrm{Fe}$ transport, and MCHC $<320 \mathrm{~g} / \mathrm{l}$ which indicates the final stage of $\mathrm{Fe}$ deficiency; Bindra \& Gibson, 1986). IDA was determined by low $\mathrm{Hb}$ concentration (males $<140 \mathrm{~g} / \mathrm{l}$, females $<120 \mathrm{~g} / \mathrm{l}$ ) combined with two or three abnormal values for indices in the tri-index model.

\section{Statistical analysis}

A statistical analysis program (SPSS 11.5 for Windows; SPSS Inc., Chicago, IL, USA) was used to analyse the data. Distribution of data was checked using the Kolmogorov-Smirnov test. When data were normally distributed, the independent samples $t$ test was used to detect differences between the groups. If data were not normally distributed, the appropriate non-parametric test was employed. Dealing with nominal data, the $\chi^{2}$ test was carried out to evaluate statistical significances. The dietary data were analysed with the use of analysis of covariance. The values representing the measurements done before the beginning of the fasting period and before the completion of the fasting period are stated as 'pre' and 'end', respectively. The dietary data analysis refers only to the $24 \mathrm{~h}$ dietary recalls due to the great number of unreturned $3 \mathrm{~d}$ weighed food records. However, previous findings of the original study have found good agreement between the two dietary assessment methods (Sarri et al. 2004).

\section{Results}

\section{Haematological status}

The mean haematological status indices for the fasting and control groups before and at the end of the CF period are shown in Table 1. Compared with the control group, the fasting group had lower pre serum ferritin $(P=0 \cdot 015)$ and higher pre MCHC $(P=0.002)$, while pre and end TIBC were also higher $(P=0.011)$ and lower $(P=0.048)$ in fasters, respectively. There were no significant differences in packed cell volume, $\mathrm{Hb}$, and transferrin saturation between the two groups at either time point.

When the changes (from pre to end time point) within the fasting group were compared with the changes within the control group (Table 1) it was found that the controls' packed cell volume levels were reduced more than the fasters $(P=0 \cdot 01)$. However, even so, mean packed cell volume values of controls were still higher than the fasters', and in both groups the packed cell volume levels were within the normal ranges ( $>36 \%$ females; $>41 \%$ males). Serum ferritin levels were increased in both groups during the fasting period, but the increase was significantly greater in the fasters compared with the controls $(P=0.02)$. There were no significant differences between the changes from pre to end values for transferrin saturation, $\mathrm{Hb}$ or serum $\mathrm{Fe}$ concentrations between the two 
Table 1. Haematological status parameters in the fasting and in the control group before the beginning (pre) and before the completion (end) of the fasting period

(Mean values and standard deviations)

\begin{tabular}{|c|c|c|c|c|c|c|c|c|c|c|c|}
\hline & & \multicolumn{4}{|c|}{ Fasting group ( $n$ 35) } & \multicolumn{4}{|c|}{ Control group (n 24) } & \multirow[b]{3}{*}{$P^{*}$} & \multirow[b]{3}{*}{$P \dagger$} \\
\hline & & \multicolumn{2}{|c|}{ Parameters } & \multicolumn{2}{|c|}{ Changes } & \multicolumn{2}{|c|}{ Parameters } & \multicolumn{2}{|c|}{ Changes } & & \\
\hline & & Mean & SD & Mean & SD & Mean & SD & Mean & SD & & \\
\hline \multirow[t]{2}{*}{ Packed cell volume (\%) } & Pre & $41 \cdot 2$ & $3 \cdot 9$ & -1.04 & $5 \cdot 18$ & $42 \cdot 7$ & $5 \cdot 1$ & -1.55 & 1.54 & NS & 0.010 \\
\hline & End & $40 \cdot 0$ & $5 \cdot 3$ & & & $41 \cdot 2$ & $5 \cdot 1$ & & & NS & \\
\hline \multirow[t]{2}{*}{$\mathrm{Hb}(\mathrm{g} / \mathrm{l})$} & Pre & $138 \cdot 0$ & $15 \cdot 0$ & $-3 \cdot 8$ & $3 \cdot 8$ & $141 \cdot 0$ & $18 \cdot 0$ & $-4 \cdot 1$ & $5 \cdot 6$ & NS & NS \\
\hline & End & $134 \cdot 0$ & $14 \cdot 0$ & & & $138 \cdot 0$ & $18 \cdot 0$ & & & NS & \\
\hline \multirow[t]{2}{*}{ Serum Fe $(\mu \mathrm{mol} / \mathrm{l})$} & Pre & $16 \cdot 9$ & $5 \cdot 8$ & -1.09 & $6 \cdot 87$ & $17 \cdot 5$ & 7.4 & 1.41 & 9.04 & NS & NS \\
\hline & End & $15 \cdot 9$ & $4 \cdot 3$ & & & $18 \cdot 5$ & $7 \cdot 4$ & & & NS $\ddagger$ & \\
\hline \multirow[t]{2}{*}{ TIBC $(\mu \mathrm{mol} / \mathrm{l})$} & Pre & $68 \cdot 4$ & 8.4 & $-8 \cdot 6$ & $6 \cdot 9$ & $63 \cdot 0$ & $7 \cdot 6$ & $1 \cdot 1$ & $5 \cdot 1$ & 0.011 & $<0.001$ \\
\hline & End & $59 \cdot 7$ & 6.9 & & & $64 \cdot 2$ & $8 \cdot 7$ & & & 0.048 & \\
\hline \multirow[t]{2}{*}{ Transferrin saturation (\%) } & Pre & $22 \cdot 7$ & $9 \cdot 1$ & $1 \cdot 22$ & $10 \cdot 16$ & $25 \cdot 5$ & $11 \cdot 2$ & $1 \cdot 78$ & $12 \cdot 76$ & NS & NS \\
\hline & End & $24 \cdot 0$ & $6 \cdot 5$ & & & $26 \cdot 7$ & $11 \cdot 9$ & & & NS & \\
\hline \multirow[t]{2}{*}{ Serum ferritin (ng/ml) } & Pre§ & 74.9 & $60 \cdot 1$ & $13 \cdot 00$ & $65 \cdot 1$ & $94 \cdot 7$ & $39 \cdot 2$ & 4.08 & $49 \cdot 9$ & 0.015 & 0.020 \\
\hline & End & $88 \cdot 8$ & $24 \cdot 6$ & & & $96 \cdot 7$ & $10 \cdot 7$ & & & NS & \\
\hline \multirow[t]{2}{*}{$\mathrm{MCHC}(\mathrm{g} / \mathrm{l})$} & Pre & $335 \cdot 0$ & $9 \cdot 0$ & -7.6 & $5 \cdot 3$ & $330 \cdot 0$ & $6 \cdot 0$ & $2 \cdot 6$ & $9 \cdot 3$ & 0.002 & $<0.001$ \\
\hline & End & $328 \cdot 0$ & $10 \cdot 0$ & & & 333.0 & $10 \cdot 0$ & & & NS & \\
\hline
\end{tabular}

$\mathrm{MCHC}$, mean corpuscular $\mathrm{Hb}$ concentration; TIBC, total Fe-binding capacity.

* Mann-Whitney $U$ test. The $P$ value refers to the comparison of pre (fasters $v$. controls) and end (fasters $v$. controls) values.

$\dagger$ Mann-Whitney $U$ test. The $P$ value refers to the comparisons of the changes within the fasting group (from pre to end fasting values) $v$. the changes within the control group. $\ddagger$ Independent $t$ test.

$\S$ Six subjects (five males, one female) had missing data for pre ferritin.

groups (Table 1). TIBC decreased from pre to end fasting in fasters by $-8.6 \mu \mathrm{mol} / 1$, and was increased in controls by $1.1 \mu \mathrm{mol} / 1$ $(P<0 \cdot 001)$ (note that a decrease in TIBC is a beneficial change as regards Fe status). MCHC levels remained almost unchanged in the control group while in the fasting group $\mathrm{MCHC}$ levels were reduced and there was a significant difference between the changes that occurred between the two groups $(P<0.001$; Table 1).
The data were also analysed for females (Table 2) and males (data not shown) separately. Pre TIBC and pre MCHC were higher in male fasters as compared with males in the control group $(P<0.001$ and $P=0.023$, respectively). In addition, male fasters significantly decreased their levels of TIBC $(P<0.001)$ and MCHC $(P<0.001)$ from pre to end time point, while the control group increased their levels (data not shown). Although there were no other significant differences between male fasters and

Table 2. Haematological status parameters of females in the fasting and in the control group before the beginning (pre) and before the completion (end) of the fasting period

(Mean values and standard deviations)

\begin{tabular}{|c|c|c|c|c|c|c|c|c|c|c|c|}
\hline & & \multicolumn{4}{|c|}{ Fasting group (n 18) } & \multicolumn{4}{|c|}{ Control group ( $n$ 13) } & \multirow[b]{3}{*}{$P^{*}$} & \multirow[b]{3}{*}{$P \dagger$} \\
\hline & & \multicolumn{2}{|c|}{ Parameters } & \multicolumn{2}{|c|}{ Changes } & \multicolumn{2}{|c|}{ Parameters } & \multicolumn{2}{|c|}{ Changes } & & \\
\hline & & Mean & SD & Mean & SD & Mean & SD & Mean & SD & & \\
\hline \multirow[t]{2}{*}{ Packed cell volume (\%) } & Pre & $38 \cdot 1$ & $2 \cdot 5$ & 0.23 & $1 \cdot 17$ & $40 \cdot 2$ & $2 \cdot 1$ & -1.44 & $1 \cdot 13$ & 0.029 & 0.003 \\
\hline & End & $38 \cdot 3$ & $2 \cdot 7$ & & & 38.6 & $2 \cdot 6$ & & & NS & \\
\hline \multirow[t]{2}{*}{$\mathrm{Hb}(\mathrm{g} / \mathrm{l})$} & Pre & $126 \cdot 0$ & $8 \cdot 0$ & -2.7 & 3.7 & $133 \cdot 0$ & $7 \cdot 0$ & -4.9 & $2 \cdot 6$ & 0.023 & 0.047 \\
\hline & End & $124 \cdot 0$ & $9 \cdot 0$ & & & $128 \cdot 0$ & 8.0 & & & NS & \\
\hline \multirow[t]{2}{*}{ Serum Fe $(\mu \mathrm{mol} / \mathrm{l})$} & Pre & $15 \cdot 9$ & $4 \cdot 7$ & -0.61 & 5.03 & $17 \cdot 3$ & $6 \cdot 6$ & $1 \cdot 19$ & $9 \cdot 12$ & NS & NS \\
\hline & End & $15 \cdot 4$ & $3 \cdot 4$ & & & $17 \cdot 7$ & $7 \cdot 0$ & & & NS & \\
\hline \multirow[t]{2}{*}{ TIBC ( $\mu \mathrm{mol} / \mathrm{l})$} & Pre & $68 \cdot 1$ & $7 \cdot 8$ & -8.69 & $6 \cdot 19$ & $63 \cdot 0$ & $8 \cdot 1$ & -0.80 & 3.82 & NS & $<0.001$ \\
\hline & End & $59 \cdot 3$ & 7.5 & & & $62 \cdot 4$ & 8.2 & & & NS & \\
\hline \multirow[t]{2}{*}{ Transferrin saturation (\%) } & Pre & $21 \cdot 6$ & $7 \cdot 7$ & 1.91 & $6 \cdot 72$ & $25 \cdot 4$ & $10 \cdot 8$ & 1.61 & $11 \cdot 21$ & NS & NS \\
\hline & End & 23.6 & $6 \cdot 1$ & & & $25 \cdot 7$ & 9.5 & & & NS & \\
\hline \multirow[t]{2}{*}{ Serum ferritin (ng/ml) } & Preł & $65 \cdot 0$ & $32 \cdot 4$ & $19 \cdot 5$ & $34 \cdot 2$ & $92 \cdot 0$ & $34 \cdot 2$ & $5 \cdot 25$ & $50 \cdot 7$ & 0.033 & 0.015 \\
\hline & End & 84.4 & $21 \cdot 1$ & & & $92 \cdot 9$ & $37 \cdot 8$ & & & NS & \\
\hline \multirow[t]{2}{*}{$\mathrm{MCHC}(\mathrm{g} / \mathrm{l})$} & Pre & $332 \cdot 0$ & $8 \cdot 0$ & $-8 \cdot 8$ & $5 \cdot 3$ & $331 \cdot 0$ & $4 \cdot 0$ & 0.20 & $9 \cdot 1$ & NS & 0.005 \\
\hline & End & $323 \cdot 0$ & $8 \cdot 0$ & & & $332 \cdot 0$ & $9 \cdot 0$ & & & 0.017 & \\
\hline
\end{tabular}

MCHC, mean corpuscular Hb concentration; TIBC, total Fe-binding capacity.

*Mann-Whitney $U$ test. The $P$ value refers to the comparison of pre (fasters $v$. controls) and end (fasters $v$. controls) values.

† Mann-Whitney $U$ test. The $P$ value refers to the comparisons of the changes within the fasting group (from pre to end fasting values) $v$. the changes within the control group. $\ddagger$ One female faster had missing data for pre ferritin. 
controls, the changes in their Fe status indices were similar to those in females. In particular, male and female fasters' $\mathrm{Hb}$, $\mathrm{MCHC}$, TIBC and serum Fe were reduced during the fasting period, while serum ferritin was increased. As for the control group, both males and females decreased their $\mathrm{Hb}$, packed cell volume, TIBC and increased ferritin, transferrin saturation, $\mathrm{MCHC}$ and serum $\mathrm{Fe}$.

Compared with males, there were more statistically significant differences between female control and fasting groups (Table 2). Females in the fasting group had lower pre packed cell volume levels $(P=0.029)$, lower pre Hb levels $(P=0.023)$, lower pre ferritin levels $(P=0.033)$ and higher end $\mathrm{MCHC}$ concentrations $(P=0.017)$. Females in the fasting group decreased their TIBC (a beneficial change) and MCHC significantly more than the females in the control group $(P<0.001$ and $P=0 \cdot 005$, respectively). Furthermore, compared with the females in the control group, females in the fasting group had overall lower levels of transferrin saturation, although this was not statistically significant, and they increased their serum ferritin levels significantly more $(P=0.015)$, although their levels were generally lower than in the control group.

Overall, there were no statistically significant differences in the percentages of subjects in the fasting or control groups that were outside cut-off points for $\mathrm{Hb}$, serum ferritin, MCHC, TIBC and serum Fe before (pre) and at the end (end) of the fasting period (data not shown). However, fewer fasters were below the cutoff point for transferrin saturation after the fasting period $(8.6 \%)$ as compared with transferrin saturation before the beginning of the fasting period $(23.5 \% ; P=0.003)$, while no such difference was observed for the controls. Although one faster and one control subject were Fe deficient according to the triindex model at the pre fasting time point, no subjects were found to be Fe deficient at end fasting either with the use of the tri-index model or with low ferritin levels $<120 \mathrm{ng} / \mathrm{l}$ (data not shown). Additionally, no subjects had IDA (data not shown).

\section{Dietary data}

Table 3 presents the mean intakes of selected macronutrients and micronutrients before and at the end of the fasting period. At baseline, total energy intake did not differ significantly between fasters and controls. However, at the end of the fasting period, fasters decreased their energy intake, while controls increased it and these levels differed significantly $(P=0 \cdot 002)$. Dietary $\mathrm{Fe}$ intake of the fasting group increased during the fasting period and was significantly higher at the end of the fasting period when compared with the control group $(P=0.038)$. Similarly, dietary fibre and vitamin $\mathrm{C}$ intake of the fasting group was higher at all time points compared with the control group, though only end dietary fibre reached statistical significance $(P=0.001)$. In contrast, pre and end protein intakes were lower in the fasting group than in the control group, but no statistical significance was found.

From $24 \mathrm{~h}$ recall questions on the consumption of food groups (data not shown), fasters reported consuming no milk, eggs, cheese or meat at the end of the CF period. Compared with the control group, the fasting group consumed more pulses at all time points, and more cereals and vegetables at pre fasting, although only the latter reached statistical significance $(P=0 \cdot 015)$. There were no other significant differences between the control and fasting group of any other food group except for the consumption of end nuts $(P=0 \cdot 010)$, which was higher in controls. In addition, compared with the control group where all subjects consumed foods of animal origin (meat, meat products, sausage, fish, seafood, cheese, milk, milk products) during the fasting period, only $30 \%$ of the fasting group consumed fish and seafood during the fasting period, while no other foods of animal origin were consumed by the fasting group at that period (data not shown).

\section{Discussion}

One of the main findings of the present study was that the religious fasting regimes of the Orthodox Christian Church which specify dietary restrictions involving a periodic vegetarian-type diet for a total of 180-200 d each year did not adversely influence the Fe status of a group of strict adherents who had been following these fasting regimes for 22 years. Furthermore, while the fasters in the present study were found to have a marginally poorer $\mathrm{Fe}$ status when compared with a group of matched

Table 3. Dietary intake of selected nutrients before the beginning (pre) and before the completion (end) of the fasting period ( $24 \mathrm{~h}$ dietary recall)

(Mean values with their standard errors)

\begin{tabular}{|c|c|c|c|c|c|c|c|c|}
\hline & & \multicolumn{3}{|c|}{ Fasting group } & \multicolumn{3}{|c|}{ Control group } & \multirow[b]{2}{*}{$P^{\star}$} \\
\hline & & $n$ & Mean & SE & $n$ & Mean & SE & \\
\hline \multirow[t]{2}{*}{ Energy intake $(\mathrm{kJ}) \dagger$} & Pre & 35 & 6967 & 2062 & 24 & 7795 & 3969 & NS† \\
\hline & End & 35 & 6098 & 2339 & 23 & 8836 & 3343 & $0.002 \dagger$ \\
\hline \multirow[t]{2}{*}{$\mathrm{Fe}(\mathrm{mg})$} & Preł & & $10 \cdot 6$ & 0.7 & & $12 \cdot 1$ & 0.8 & NS \\
\hline & End & & $14 \cdot 8$ & 0.6 & & $12 \cdot 6$ & 0.7 & 0.038 \\
\hline \multirow[t]{2}{*}{ Protein $(\mathrm{g})$} & Pre & & $55 \cdot 8$ & 2.9 & & $60 \cdot 4$ & 3.6 & NS \\
\hline & End $\ddagger$ & & $47 \cdot 7$ & 2.9 & & $59 \cdot 9$ & 3.7 & NS \\
\hline \multirow[t]{2}{*}{ Fibre (g) } & Pre & & $19 \cdot 4$ & $1 \cdot 1$ & & $17 \cdot 2$ & 1.4 & NS \\
\hline & End & & $29 \cdot 6$ & 1.7 & & $18 \cdot 7$ & $2 \cdot 2$ & 0.001 \\
\hline \multirow[t]{2}{*}{ Vitamin C (mg) } & Pre & & $108 \cdot 0$ & $10 \cdot 4$ & & $104 \cdot 2$ & $12 \cdot 6$ & NS \\
\hline & End & & $153 \cdot 3$ & $20 \cdot 4$ & & $142 \cdot 6$ & $25 \cdot 9$ & NS \\
\hline
\end{tabular}

*Analysis of covariance. The values are adjusted for sex, age, pre BMI and pre energy intake (for the pre values), end BMI and end energy intake (for the end values).

† Energy intake was analysed with the independent samples $t$ test. The unadjusted values are presented as means and SD.

$\ddagger$ Due to heterogeneity, $\log _{10}$ transformation was used. 
omnivores (control group) before the start of the CF period, all the $\mathrm{Fe}$ status indices measured were well above the cut-off points for poor Fe status. Several other studies have found few or no differences in $\mathrm{Fe}$ status when comparing omnivores with vegetarians (Harman \& Parnell, 1998; Haddad et al. 1999; Hunt, 2003). It is generally accepted that although several studies in Western countries have shown lower levels of $\mathrm{Fe}$ stores in vegetarians, there does not appear to be a greater incidence of IDA in vegetarians (Hunt, 2003). Furthermore, it has been reported (Committee on Diet and Health, National Research Council, 1989) that in Western countries, IDA appears to be no more prevalent among vegetarian women than among nonvegetarian women.

As in the present study, where the fasting group had significantly lower MCHC levels after following a vegetarian-type diet as compared with the control group, Pongstaporn \& Bunyaratavej (1999) found that vegetarians had lower MCHC levels and this was inversely correlated with the years of adherence to vegetarianism. The inverse association between the duration of vegetarianism has been reported previously (Anderson et al. 1981; Pongstaporn \& Bunyaratavej, 1999) with several Fe status indices, such as packed cell volume, $\mathrm{Hb}$ and serum ferritin, even when levels are well within the normal range. Additionally, the reduced levels of MCHC observed in the present study could also be explained by the relatively lower levels of $\mathrm{Hb}$, as MCHC is a measure of $\mathrm{Hb}$ in a given volume of erythrocytes.

Interestingly, the changes in Fe status indices that occurred over the CF period in males and females as a whole (Table 1) and in females separately (Table 2), appeared to be more positive in the fasting group. However, overall concentrations of these Fe status indices were better in the control group than in the fasting group. As regards the effect of the CF period on Fe status, it is difficult to compare the present results with other studies due to the fact that no other studies have been carried out in similar populations. However, there are two cross-over-design studies that investigated the effect of interchanging from vegetarian to omnivore diets for 8 (Hunt \& Roughead, 1999) and 12 weeks (Wells et al. 2003) on Fe status, which are the closest that we could find to the present study's characteristics and duration (6-7 weeks). In agreement with the present results, neither of these studies reported any significant effect of the changing to a vegetarian diet on Fe status. However, Hunt et al. (1995) reported that 7 weeks was enough time to have an impact on $\mathrm{Fe}$ status, although the beneficial effect found was not what the authors had expected.

The fasters in the present study had significantly higher $\mathrm{Fe}$ intake at the end of the fasting period and as they did not consume any meat or dairy products and did not take any Fe supplements during the $\mathrm{CF}$ period all the $\mathrm{Fe}$ consumed by them must have been in the non-haem form. Although non-haem-Fe is less bioavailable, it has been suggested (Cook et al. 1974; Hunt \& Roughead, 2000) that subjects with lower Fe stores tend to absorb much more non-haem-Fe than those with normal or high $\mathrm{Fe}$ stores. This could possibly enhance their Fe status, increase their ferritin levels and protect them from any deficiencies over time and explain why we did not see any adverse effect on Fe status.

No differences were found in the percentages of subjects in the fasting and control groups that were below the cut-off points for poor Fe status, either before or after the CF period, in agreement with the studies by Shaw et al. (1995) and Donovan \& Gibson (1995). No subjects with IDA were found in the present study, which could be attributed to the similar dietary intakes of fasters and controls and to the fasters' infrequent interchange from an omnivorous to a periodic vegetarian-type diet or to the small sample size. Thus while $40 \mathrm{~d}$ of fasting over the Christmas period may not have been long enough to influence $\mathrm{Fe}$ status indices to such an extent, $22.5 \pm 15.5$ years of regular fasting for religious reasons did not appear to result in a greater proportion of the fasters having $\mathrm{Fe}$ status indices outside of the recommended cut-offs either. Contrary to other studies (Bindra \& Gibson, 1986; Waldmann et al. 2004), there was no difference in the prevalence of Fe deficiency when applying the serum ferritin cut-off values or the tri-index model in the present study.

There are several limitations associated with the present study. A power calculation was not used in determining sample sizes because the study of Fe status and anaemia was not part of the original study's objectives. Due to the large proportion of unreturned $3 \mathrm{~d}$ weighed food records, the assessment of nutrient intake was limited to the use of the $24 \mathrm{~h}$ dietary recall, which generally give an estimate of the average nutrient intake. There also might be some selection bias since all the subjects were volunteers. Furthermore, only one sample per subject was analysed for serum ferritin, while three or more blood samples are ideally required to determine serum ferritin accurately because of day-today variation (Cooper \& Zlotkin, 1996). However, several studies have been published using single samples (Shaw et al. 1995; Wells et al. 2003). Finally, no information on females' menstruation status or use of hormonal contraceptives was collected (Hunt \& Roughead, 1999).

In summary, the present findings suggest that the fasting regimes of the Orthodox Christian Church, which specify a periodic vegetarian-type diet at regular intervals for between 180 and $200 \mathrm{~d}$ each year, do not adversely influence the Fe status or increase the risk of IDA. It has been previously reported that adherents to the Orthodox Church's dietary guidelines have lower total cholesterol, LDL-cholesterol, LDL:HDL-cholesterol ratio and BMI (Sarri et al. 2003) and consume diets that are lower in total fat, saturated fatty acids and dietary cholesterol and higher in fibre, folate and Fe compared with control subjects (Sarri et al. 2004). Thus, our present results, in conjunction with previous findings in the same population (Sarri et al. 2003, 2004) and the significantly lower prevalence of CVD found in Greece compared with other countries in the Seven Countries Study in the 1960s (Menotti et al. 1999, 2001), would suggest that promoting the dietary guidelines of the Orthodox Christian Church could have potential long-term health benefits. Furthermore, promotion of the Orthodox Christian Church's dietary guidelines could be an effective health promotion strategy in this population as it would be easier for individuals to follow it, not only because Greece is a highly religious and traditional country, but also because individuals would be familiar with this type of recommendation and they would be able to meet both their spiritual and physical needs.

\section{Acknowledgements}

The authors are grateful to the Department of Biochemistry of the Royal Glasgow Infirmary, the Department of Haematology of the Yorkhill Hospital and the Department of Biochemistry at the Peripheral Hospital of Crete for analysing our samples, and appreciate the assistance of Mr Manolis Linardakis. 


\section{References}

Alexander D, Ball MJ \& Mann J (1994) Nutrient intake and haematological status of vegetarians and age-sex matched omnivores. Eur J Clin Nutr 48, 538-546.

Anderson BM, Gibson RS \& Sabry JH (1981) The iron and zinc status of long-term vegetarian women. Am J Clin Nutr 34, 1042-1048.

Bindra GS \& Gibson RS (1986) Iron status of predominantly lactoovo vegetarian East Indian immigrants to Canada: a model approach. Am J Clin Nutr 44, 643-652.

Committee on Diet and Health, National Research Council (1989) Diet and Health: Implications for Reducing Chronic Disease Risk. Washington, DC: National Academy Press.

Cook JD, Lipschitz DA, Miles LE \& Finch CA (1974) Serum ferritin as a measure of iron stores in normal subjects. Am J Clin Nutr 27, 681-687.

Cooper MJ \& Zlotkin SH (1996) Day-to-day variation of transferrin receptor and ferritin in healthy men and women. Am J Clin Nutr 64, 738-742.

Donovan UM \& Gibson RS (1995) Iron and zinc status of young women aged 14 to 19 years consuming vegetarian and omnivorous diets. J Am Coll Nutr 14, 463-472.

Haddad EH, Berk LS, Kettering JD, Hubbard RW \& Peters WR (1999) Dietary intake and biochemical, hematologic, and immune status of vegans compared with nonvegetarians. Am J Clin Nutr 70, 586S-593S

Harman SK \& Parnell WR (1998) The nutritional health of New Zealand vegetarian and non-vegetarian Seventh-day Adventists: selected vitamin, mineral and lipid levels. $N$ Z Med J 111, 91-94.

Helman A \& Darnton-Hill I (1987) Vitamin and iron status in new vegetarians. Am J Clin Nutr 45, 785-789.

Hercberg S, Preziosi P \& Galan P (2001) Iron deficiency in Europe. Public Health Nutr 4, 537-545.

Hunt JR (2003) Bioavailability of iron, zinc, and other trace minerals from vegetarian diets. Am J Clin Nutr 78, Suppl. 3, 633S-639S.

Hunt JR, Gallagher SK, Johnson LK \& Lykken GI (1995) High- versus low-meat diets: effects on zinc absorption, iron status, and calcium, copper, iron, magnesium, manganese, nitrogen, phosphorus, and zinc balance in postmenopausal women. Am J Clin Nutr 62, 621-632.

Hunt JR \& Roughead ZK (1999) Nonhaem-iron absorption, fecal ferritin excretion, and blood indexes of iron status in women consuming controlled lactoovovegetarian diets for $8 \mathrm{wk}$. Am J Clin Nutr 69, 944-952.
Hunt JR \& Roughead ZK (2000) Adaptation of iron absorption in men consuming diets with high or low iron bioavailability. Am J Clin Nutr 71, 94-102.

Leggett BA, Brown NN, Bryant SJ, Duplock L, Powell LW \& Halliday JW (1990) Factors affecting the concentrations of ferritin in serum in a healthy Australian population. Clin Chem 36, 1350-1355.

Menotti A, Blackburn H, Kromhout D, Nissinen A, Adachi H \& Lanti M (2001) Cardiovascular risk factors as determinants of 25-year all-cause mortality in the seven countries study. Eur J Epidemiol 17, 337-346.

Menotti A, Kromhout D, Blackburn H, Fidanza F, Buzina R \& Nissinen A (1999) Food intake patterns and 25-year mortality from coronary heart disease: cross-cultural correlations in the Seven Countries Study. The Seven Countries Study Research Group. Eur J Epidemiol 15, 507-515.

Patterson AJ, Brown WJ, Roberts DC \& Seldon MR (2001) Dietary treatment of iron deficiency in women of childbearing age. Am J Clin Nutr 74, 650-656.

Pongstaporn W \& Bunyaratavej A (1999) Hematological parameters, ferritin and vitamin B12 in vegetarians. J Med Assoc Thai 82, 304-311.

Sarri K, Linardakis M, Bervanaki F, Tzanakis N \& Kafatos A (2004) Greek Orthodox fasting rituals: a hidden characteristic of the Mediterranean diet of Crete. Br J Nutr 92, 277-284.

Sarri KO, Tzanakis NE, Linardakis MK, Mamalakis GD \& Kafatos AG (2003) Effects of Greek Orthodox Christian Church fasting on serum lipids and obesity. BMC Public Health 3, 16.

Seidel J (1984) Improved ferrozine based reagent for the determination of serum iron without deproteinisation. Clin Chem 30, 975.

Shaw NS, Chin CJ \& Pan WH (1995) A vegetarian diet rich in soybean products compromises iron status in young students. J Nutr $\mathbf{1 2 5}$ $212-219$.

Tsung SH, Rosenthal WA \& Milewski KA (1975) Immunological measurement of transferrin compared with chemical measurement of total iron-binding capacity. Clin Chem 21, 1063-1066.

Waldmann A, Koschizke JW, Leitzmann C \& Hahn A (2004) Dietary iron intake and iron status of German female vegans: results of the German vegan study. Ann Nutr Metab 48, 103-108.

Wells AM, Haub MD, Fluckey J, Williams DK, Chernoff R \& Campbell WW (2003) Comparisons of vegetarian and beef-containing diets on hematological indexes and iron stores during a period of resistive training in older men. J Am Diet Assoc 103, 594-601. 